\title{
"Lifeblood knowledge": dynamic relational capabilities (DRC) and knowledge for firm innovativeness and competitive advantage
}

\author{
Marion Weissenberger-Eibl and Johann Schwenk
}

\author{
Marion Weissenberger-Eibl \\ and Johann Schwenk are \\ both based at the \\ Department of Innovation \\ and Technology \\ Management, University of \\ Kassel, Kassel, Germany.
}

\begin{abstract}
Summary
Purpose - The purpose of the underlying paper is to strengthen and develop the theory around (dynamic) relational capabilities for firm innovativeness and competitive advantage with focus on the resource knowledge. Therefore one objective is the development of a theoretical concept of DRC within the research fields of social system-theory, relational and capability-based view. Another goal is the evolvement of the four DRC concerning the interorganizational knowledge transfer between firms.

Design/methodology/approach - The theoretical part is based on a literature analysis in strategic management research. The authors propose a theoretical framework - DRC - predicated on social system-theory, relational and capability-based view. The discussion concludes by providing management implications for implementation of DRC to practitioners in firms.

Findings - The outcome of this paper contributes to the underlying conceptual work for strategic and knowledge management of firms. In detail a theoretical concept - DRC - for managing knowledge to generate innovativeness and competitiveness is developed. Furthermore, the paper provides some management implications on macro-, meso-, and micro-level of firms to implement them.

Practical implications - For practitioners the paper gives implications for implementing the theoretical considerations.

Originality/value - The concept has proven to be useful in improving the interorganizational knowledge transfer and innovativeness and competitive advantage in firms.

Keywords Knowledge management, Innovation, Competitive strategy

Paper type Conceptual paper

\section{Introduction}

Regarding a dynamic socio-economic environment (Fitzroy and Hulbert, 2005), the dominating approach of RBV (Barney et al., 2001), with knowledge as essential component (Drucker, 1991; Nonaka, 1991; Schiuma and Lerro, 2008), has to be extended with an external perspective (Teece, 2007). The relational view as co-evolution of RBV initiated by Dyer and Singh (1998) focuses on this task. This approach offers "a view that suggests that a firm's critical resources may span firm boundaries and may be embedded in interfirm resources and routines". Regarding innovativeness and competitiveness of firms they state four capabilities concerning relationship between firms:
\end{abstract}

(1) relation-specific assets, (2) knowledge-sharing routines, (3) complementary resources/ capabilities, and (4) effective governance (Dyer and Singh, 1998, p. 660).

Dyer and Hatch (2006) and Capaldo (2007) evolve the discussion of relational capabilities of knowledge transfer in interfirm networks.

Cause of a changing business environment interorganizational capabilities have to be adapted and modified equally (Peteraf and Maritan, 2007). Due to their contextual closeness to the dynamic capabilities of Teece et al. (1997), their integration in this approach supports this task. The developed DRC enable firms the ongoing optimization of interorganizational 
relationships and contributes to economic success. Important is the generated access and possible exchange of knowledge over firm boundaries (Ahuja, 2000; Dagnino, 2005; Duschek, 2004; Lanza, 2005).

Acedo et al. (2006) and Newbert (2007) in meta-analysis discuss the relational and capability-based view as main trends in future strategic research. However, their foundations are still in their infancy and the theoretical as well as their practical implementation are still in flux (Capaldo, 2007). Consequently, the purpose of the paper is to develop and strengthen the theory around DRC for firm innovativeness and competitive advantage with focus on the resource knowledge through analyzing, the following key issues:

- How can a theoretical fundament of DRC under consideration of aspects of social system-theory, relational and capability-based view be defined?

- How can the four DRC, especially knowledge-sharing routines for interorganizational knowledge transfer, concerning the relationship between firms be evolved?

- What are the implications for the management regarding the implementation of DRC?

In detail following points will be argued:

1. The first step is connected with aspects of social system-theory (Luhmann, 1995), which provides interesting linkages to relational (Dyer and Singh, 1998) and capability based view (Teece, 2007). Crucial is the inherent idea of innovativeness and competitive advantage through capabilities for interorganizational relationship and the interaction of resources within (Dyer and Hatch, 2006).

2. Secondly, the four capabilities: relation-specific assets, knowledge-sharing routines, complementary resources/capabilities, and effective governance (Dyer and Singh, 1998) are discussed and developed. Especially knowledge-sharing routines and a referring knowledge-management process are highlighted (Dyer and Kale, 2007).

3. Thirdly, the discussion results in implications to the management of firms concerning DRC. Concrete points on the macro-, meso-, and micro-level of the firm are given.

\section{Firms as social systems and DRC}

Including ideas of Wiener (1975), Ashby (1956, p. 4) develops the field of cybernetics and emphasizes its importance "for the scientific treatment of the system in which complexity is outstanding". Parsons' (1971) research in which (social) systems compose the primary frame of reference, forms the next step of evolution. As central finding, Parsons states social systems based on the difference between themselves determined trough interaction and communication. Luhmann's (1995) work which uses Parsons' ideas for evolution of the underlying subject is always oriented on the genesis of a general theory of social systems. According to Luhmann, the system-environment paradigm is essential. Consequently, the system constitutes itself through recursive communication and exchange of information between system and environment, based on the self-referential self-perception and connected differences.

Taking these ideas into account external knowledge interaction builds the fundament of success of firms:

The environment of the organization is largely beyond the knowledge and control of the people within it: they cannot know everything about every aspect of the world within which the organization operates (Espejo et al., 1996, p. 106).

This illuminates two aspects:

1. A firm which exists in a dynamic environment where knowledge is extremely growing cannot posses all relevant knowledge resources by itself.

2. Therefore it is necessary, that firms search and generate the right contacts to get access to the external resource knowledge. 
The ideas regarding innovativeness and competitive advantage can be adapted out of the relational view. Dyer and Singh (1998, p. 660) argue that an "increasingly important unit of analysis for understanding competitive is the relationship between firms" and the resources that flows in them. Knowledge constitutes here as critical resource, as well as their underlying relational capabilities. Therefore, as result for the theoretical foundation of DRC, we can state the social system-theory as a possible approach. Figure 1 clarifies the adequateness of social system-theory of firms designed by recursive communication within the environment in combination with the idea of interorganizational knowledge exchange.

Dyer and Singh (1998) established four relational capabilities. The first is the relation-specific assets of the firm, which concerns the genesis of specialized assets in conjunction with them of their collaborating partners. The second are the interfirm knowledge-sharing routines, which are strongly related to partner-specific absorptive capacity (Cohen and Levinthal, 1990). The third aspects are complementary resources/capabilities within and between firms. The general inherent idea is the overlapping, the complementarity of partners through a similar strategic direction. The fourth relational capability is effective governance, which includes basal reflection of institutional economics (Williamson, 1975).

In a fast changing environment firm capabilities have to be dynamized. First steps in this discussion have been done, e.g. by Dyer and Hatch (2006) through a confrontation with relational and capability based view in form of relational capabilities. Teece's (2007) considerations for development of dynamic-capability approach, also involve relational aspects regarding the capability to collaborate with other firms. With reference to the definition of dynamic capabilities (Teece et al., 1997, pp. 516-518), which states them as "the firms ability to integrate, build and reconfigure internal and external competences to address rapidly changing environments" and as "organizational processes shaped by the firms asset positions and molded by its evolutionary and co-evolutionary paths" an

\section{Figure 1 Recursive interorganizational knowledge transfer between firms}

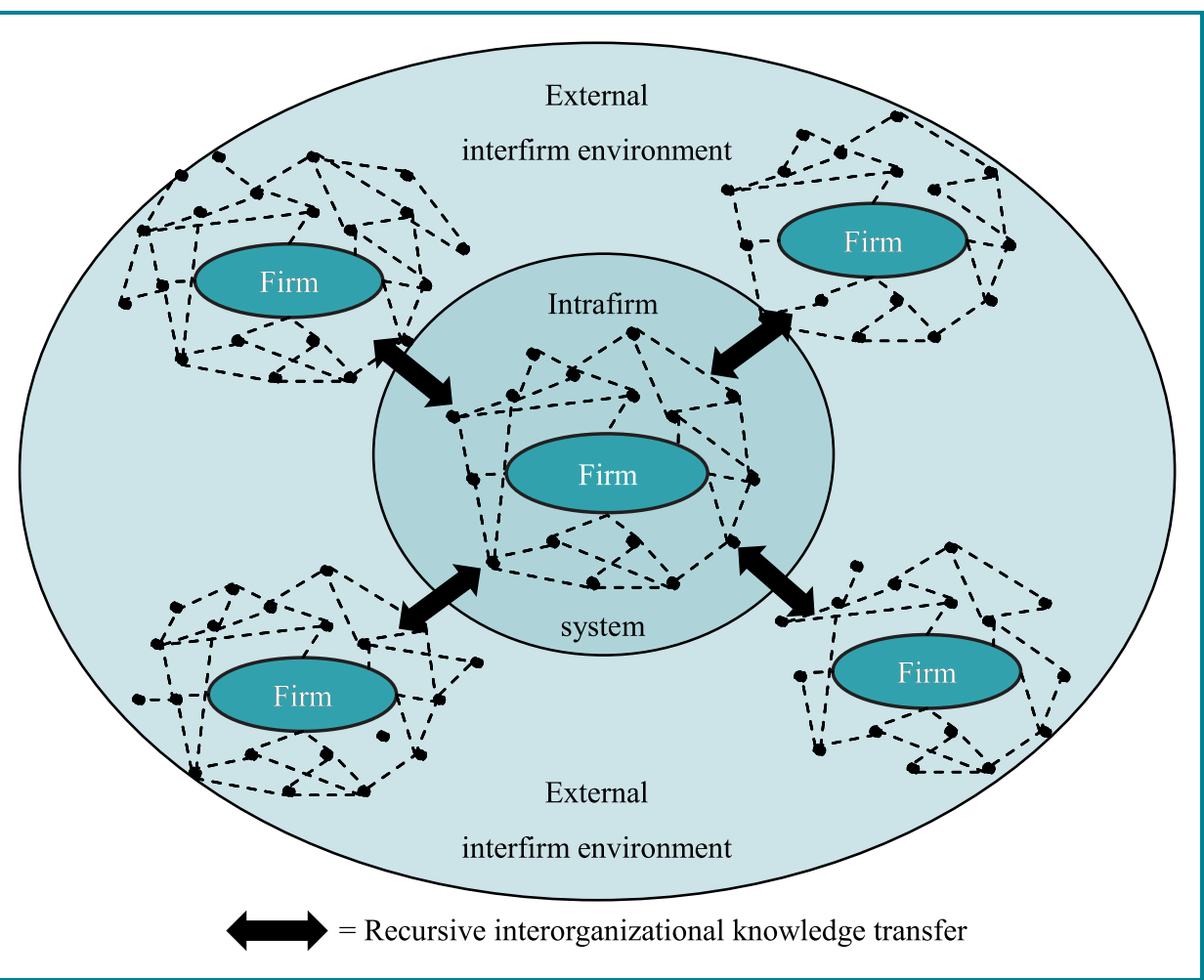


integration of relational capabilities in the dynamic-capability approach for their dynamization can be implemented (Figure 2).

Organizational processes as core of DRC are diversified in the term of Teece et al. (1997) in the processes coordination/integration, learning and reconfiguring. Eisenhardt and Martin (2000), Winter (2003), Schreyögg and Kliesch-Eberl (2007), and Teece (2007) enhanced and refined DRC.

We suggest as interim conclusion social system-theory as theoretical base in combination with ideas of relational and (dynamic) capability based view for an approach of DRC for firm innovativeness and competitiveness. Central to this attempt is the resource knowledge and its interorganizational transfer between firms.

\section{DRC and lifeblood knowledge}

DRC let firms evolve in relation to a dynamic changing environment. The next section discusses two parts based on the above considerations. Firstly, a detailed controversy of the four DRC and their further development. Secondly, the capability of knowledge-sharing routines and integrate it in a knowledge-management process.

\section{Further development}

Relation-specific assets. Regarding the RBV of the firm resources have to be different and unique in comparison to competitors to generate competitive advantage (Barney, 1991). In our context this means the evolution of specialized assets in collaboration with alliance partners through an interorganizational firm network (Dyer and Hatch, 2006). According to Williamson (1975) there are three types of assets. Site specificity, which refers to close production stages and related investment to reduce transportation and coordination costs. Physical asset specificity, which concerns transaction-specific capital investments. Human asset specificity, which is related to transaction-specific knowledge built trough sustained relationships. Considering this institutional economics oriented points it seems appropriate

\section{Figure 2 Dynamic relational capabilities in a rapidly changing environment}

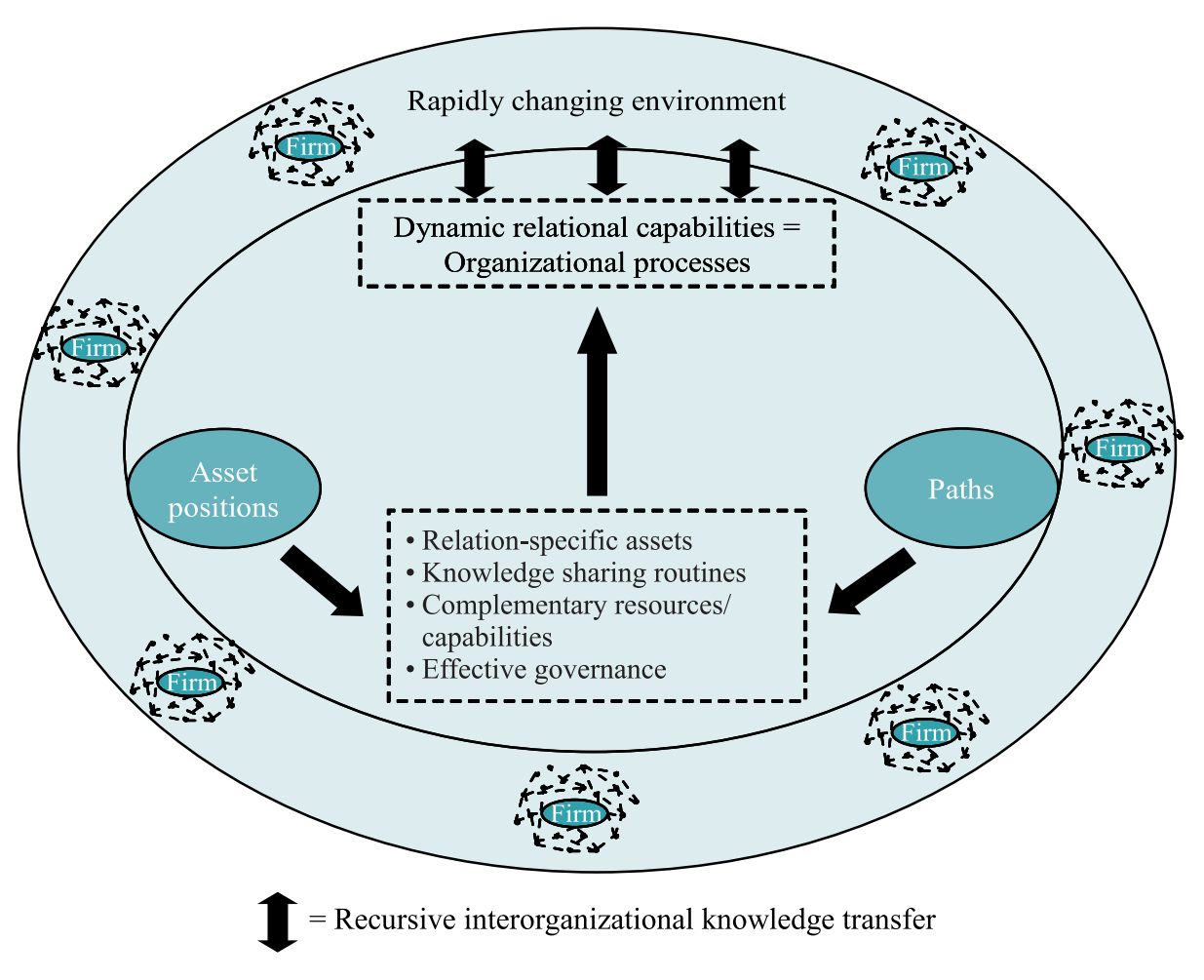

PAGE $10 \mid$ MEASURING BUSINESS EXCELLENCE $\mid$ VOL. 13 NO. 22009 
to integrate "trust" as an essential element in an early stage of creating relation-specific assets (Williamson, 1975). Investments for this attempt are the co-specialization of personnel (Dyer and Kale, 2007).

Knowledge sharing routines. Successful knowledge sharing routines see partner-specific absorptive capacity and the incentives to establish firm transparency as critical determinants. Regarding Cohen and Levinthal (1990, p. 128) absorptive capacity is "the ability of a firm to recognize the value of new, external information, assimilate it, and apply it to commercial ends." Furthermore, they suggest that it is "largely a function of the firm's level of prior related knowledge." These considerations have to be adapted for corresponding knowledge basis of collaborating firms. Following March and Simon (1958) common shared background knowledge is crucial. For new insights also non-overlapping specialized knowledge is important (Lane et al., 2006). To realize an optimized interorganizational knowledge transfer Dyer and Kale (2007) suggest a knowledge-management process consisting of articulation, codification, sharing and internalization.

Complementary resources/capabilities. Complementary resources/capabilities emerge through common work experience, investments in R\&D assets as well as through an information-rich position in social networks. Essential for this is the optimized cooperation through a strategic fit between firms. Hamel and Prahalad (1989) and Zajac et al. (2000) show the importance of strategic intent and strategic fit into and between firms:

The ability of alliance partners to generate relational rents from complementary strategic resources increases with the degree of compatibility in their organizational systems, processes, and cultures (Dyer and Singh, 1998, p. 668).

In our nexus of firms as social systems with knowledge as central resources, especially the information enriched position in networks is interesting. For this contribution the positions of "tertius gaudens" and "tertius lungens" out of ideas regarding social networks will be used. "The tertius gaudens is the third who benefits" so Burt (1992, p. 30) and names two strategies:

(...) being the third between two or more players after the same relationship, and being the third between players in two or more relations with conflicting demands.

The related tertius lungens (Obstfeld, 2005, p. 100) is the one who connects "people in their social network by either introducing disconnected individuals or facilitating new coordination between connected individuals."

Effective governance. The fourth DRC is effective governance. Dyer and Singh (1998, p. 670) say:

The greater the alliance partners' ability is to align transactions with governance structures in a discriminating (...) way, the greater the potential will be for relational rents.

According to Williamson (1975, pp. 106) we highlight trust in cooperations as key issue. If trust rests on contractual completeness and exacting execution, businessmen will experience that "such transactional attitudes result in excessive costs and render their businesses nonviable. Next to long-term common work experience, successful accomplished projects, trust as social capital raises through social connections and the exchange of analog knowledge - shared aims, hobbies etc. - which are building confidence, trust, and connection"' (Cohen and Prusak, 2001).

\section{Knowledge-sharing routines and knowledge-management process}

In order to discuss the knowledge-management process the term knowledge and its understanding has to be declared. In literature a lot of work has been done on the concept of knowledge (Davenport and Prusak, 1998; Habermas, 1978; Polanyi, 1967; Sackmann, 1992). So far no homogeneous and fully accepted definition prevails. One of the widely accepted conceptualization of knowledge includes the differentiation between data, information and knowledge. The generally accepted view sees data as simple facts that become information as data are combined into meaningful structures, which subsequently 
become knowledge as meaningful information is put into a context and when it can be used to make predictions. This hierarchy from data to information to knowledge illuminates some interesting overlapping ideas with the theory of radical constructivism of knowledge. Concerning von Glasersfeld (1987), knowledge is a self-organized cognitive process of human brains influenced by experience and embedding it in an individual, unique context. Radical Constructivism delivers important aspects of knowledge-sharing routines and a knowledge-management process:

- Interorganizational knowledge transfer between firms cannot be realized through the simple exchange of data, or information using sheets or tools of ICT.

- It is essential to develop a common context, a common background, to enable the design of a similar knowledge, a similar layout of the apprehended world.

Regarding an optimized interorganizational knowledge transfer, Dyer and Kale (2007) state a knowledge-management process consisting of four linear followed stages. Examining the stages we suggest developing this process into a knowledge-management circle (Figure 3).

Within this closed cycle every stage builds the fundament of the next. Articulation of which knowledge is existing in firms, builds the basic consideration for codification of knowledge in a next step. An important part of knowledge-management is "the development of codified explicit knowledge about managing various stages of evolution of an alliance" (Dyer and Kale, 2007, p. 73). It is comparatively difficult to handle tacit knowledge because it is connected with personal experience and contexts. For the next stage of knowledge sharing tacit knowledge within common background knowledge is more crucial. Sharing the capability of every individual to explicate, encode, and communicate information and knowledge with other individuals is crucial. In any case existent overlapping knowledge and so (partner specific) absorptive capacity are mandatory determinant (Cohen and Levinthal, 1990). To internalize knowledge in the next stage is to integrate new information in a sense-making context to generate useful knowledge for firm targets. Concerning Grant (1996) organizing mechanism rules and directives, sequencing, routines, and group problem solving are accountable to internalize knowledge. This process extends firms knowledge base so that knowledge articulation has being affected. The knowledge-management circle starts again.

\section{Figure 3 Knowledge-management circle}

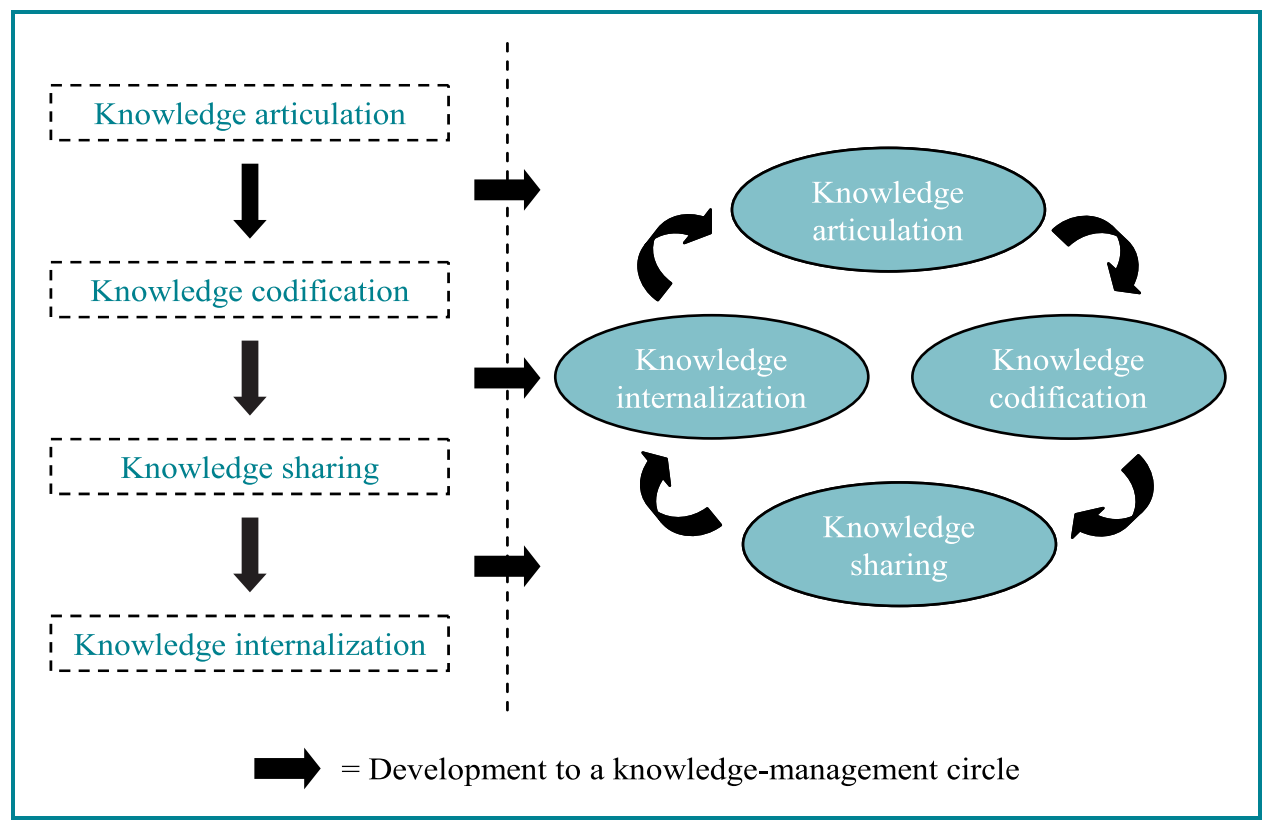

PAGE 12 MEASURING BUSINESS EXCELLENCE | VOL. 13 NO. 22009 
The underlying paper focuses on the development of DRC for inter-organizational knowledge transfer and firm innovativeness and competitive advantage. Concerning these discussed points management implications for their implementation in firms are given.

\section{Macro-level}

On macro-level of firms we focus on three design fields: culture, structure and strategy. Taking Schein's (1990, p. 9) term of cultural systems as "a pattern of basic assumptions invented, discovered, or developed by a given group" for firms it is clear that open communication in general is central. Mental programming (Hofstede, 1980) accordingly sees culture as the emergence of common setting and values build trough socialization. For socialization of communication friendly culture two aspects should be named. Firstly, the commitment of management is important to set an example by itself. Secondly, the considerations of the "personal fit" in recruiting processes are crucial. A useful tool for this purpose is the "organizational culture profile", which uses cultural items to test the cultural fit (O'Reilly et al., 1991). The environment is rapidly changing so that "regulatory and institutional structures must constantly be reshaped" (Teece, 2007, p. 1321). Crucial for reand new-shaping is the self-reference of firms including recursive exchange with the environment. Organizational structures oriented on firm development as well as on the changes of markets have to serve the fast moving environment organized decentralized and strongly flexible away from functional to multidivisional forms. Fluid modular structures adapted on management by objectives seem to be appropriate (Teece, 2007). Management implications regarding strategy of firms for implementing DRC are tautological. The strategy to generate DRC should set on relational and capability-based view (Dyer and Singh, 1998; Teece, 2007). Important is that this views are an evolution of RBV (Wernerfelt, 1984) with knowledge as crucial lifeblood. Consequently, management has to realize a strategy within innovativeness and competitive advantage realized through knowledge exchange over inter-organizational boundaries enabled through DRC.

\section{Meso-level}

The meso-level of firms continues the debate for implementation of DRC, around flexibilization of organizational structures. Developing DRC can be supported by structuring the team level in hypertexts. Nonaka (1994), who deduced this organization-form from an internet-based data model which connects different aspects non-hierarchical and enables the solution-oriented combination of diversified knowledge. Mills' (1991) cluster model helps us to organize hypertexts over firm boundaries, by seeing a cluster as less structured, organic combination of largely discrete organization units. Operating units temporary come together over boundaries to solve objects. Another aspect of communication across boundaries are special boundary roles (Tushmann, 1977). "Boundary spanner" act at the interface of firms and build a communication medium between them. Their primary functions of acquiring information and representing are recursive (Aldrich and Herker, 1977; Ethiray and Levinthal, 2004). Considerations of Ancona and Caldwell (1992) support these suggestions and Kickul and Gundry (2001) confirm their raising importance.

\section{Micro-level}

The micro-level of the firm concerns communication via speech and regarding cognitive capabilities of employees. Spoken agreement requests the identical interpretation of expression and therefore the integration of spoken words in an equivalent context. Thus, shared background knowledge and common experiences are necessary. March and Simon (1958) suggest to reach this target within the cooperation in daily work and in common trainings. COP over firm boundaries are another parameter for realizing common contexts (Wenger, 1998). Affects on cognitive capabilities are connected with the amount of processing information. Verbal intelligence, inductive and deductive thinking, and the memory of human beings are competences for communication between firms (Robbins, 2003). These aspects should be considered in HR in general and in recruitments especially. 


\section{Conclusions}

This paper discussed DRC and knowledge for firm innovativeness and competitive advantage. The first objective to strengthen the theory around this topic is reached through the development of a (social) system-based fundament in combination with the relational and capability-based view. The next step is the enhancement of DRC. Integration of knowledge-sharing routines in a knowledge-management process and its enhancement to a knowledge-management circle builds an outstanding role. The paper concludes with management implications for the implementation of DRC. Some aspects on the macro-, meso-, and micro-level of firms could be explicated. We have shown that developing DRC support the transfer of lifeblood knowledge between firms and so innovativeness and competitive advantage.

Despite new insights in theory and practical implications there is potential for future research. This paper suggests some theoretical and practical lines but DRC can still be stated to be in their infancy. Both main theory building aspects regarding the fundaments of these capabilities and aspects concerning managerial implications should be further developed.

\section{References}

Acedo, F.J., Barroso, C. and Galan, J.L. (2006), "The resource-based theory: dissemination and main trends", Strategic Management Journal, Vol. 27, pp. 621-36.

Ahuja, G. (2000), "Collaboration networks, structural holes and innovation: a longitudinal study", Administrative Science Quarterly, Vol. 45, pp. 425-55.

Aldrich, H. and Herker, D. (1977), "Boundary spanning roles and organization structure", Academy of Management Review, Vol. 2, pp. 217-30.

Ancona, D.G. and Caldwell, D.F. (1992), "Bridging the boundary: external activity and performance in organizational teams", Administrative Science Quarterly, Vol. 37, pp. 634-65.

Ashby, W.R. (1956), An Introduction to Cybernetics, Chapman \& Hall, London.

Barney, J. (1991), "Firm resources and sustained competitive advantage", Journal of Management, Vol. 17, pp. 99-120.

Barney, J., Wright, M. and Ketchen, D.J. Jr (2001), "The resource-based view of the firm: ten years after 1991", Journal of Management, Vol. 27, pp. 625-41.

Burt, R.S. (1992), Structural Holes: The Social Structure of Competition, Harvard University Press, Cambridge.

Capaldo, A. (2007), "Network structure and innovation: the leveraging of a dual network as a distinctive relational capability", Strategic Management Journal, Vol. 28, pp. 585-608.

Cohen, D. and Prusak, L. (2001), In Good Company: How Social Capital Makes Organizations Work, Harvard Business School Press, Boston, MA.

Cohen, W.M. and Levinthal, D.A. (1990), "Absorptive capacity: a new perspective on learning and innovation", Administrative Science Quarterly, Vol. 35, pp. 128-52.

Dagnino, G. (2005), "Coupling combinative and relational capabilities in interorganizational best practice transfer", in Capasso, A., Dagnino, G.B. and Lanza, A. (Eds), Strategic Capabilities and Knowledge Transfer within and between Organizations, Edward Elgar, Cheltenham, pp. 103-44.

Davenport, T. and Prusak, L. (1998), Working Knowledge, Harvard University Press, Cambridge, MA. Drucker, P.F. (1991), "The new productivity challenge”, Harvard Business Review, Vol. 69, pp. 69-79.

Duschek, S. (2004), "Inter-firm resources and sustained competitive advantage", Management Revue, Vol. 15, pp. 53-73.

Dyer, J.H. and Hatch, N.W. (2006), "Relation-specific capabilities and barriers to knowledge transfers: creating advantage through network relationships", Strategic Management Journal, Vol. 27, pp. 701-19. 
Dyer, J.H. and Kale, P. (2007), "Relational capabilities: drivers and implications", in Helfat, C.E., Finkelstein, S., Mitchell, W., Peteraf, M.A., Singh, H., Teece, D.J. and Winter, S.G. (Eds), Dynamic Capabilities: Understanding Strategic Change in Organizations, Blackwell, Oxford, pp. 65-79.

Dyer, J.H. and Singh, H. (1998), "The relational view: cooperative strategy and sources of interorganizational competitive advantage", Academy of Management Review, Vol. 23, pp. 660-79.

Eisenhardt, K.M. and Martin, J.A. (2000), "Dynamics capabilities: what are they?", Strategic Management Journal, Vol. 21, pp. 1105-21.

Espejo, R., Schumann, W., Schwaninger, M. and Bilello, U. (1996), Organizational Transformation and Learning: A Cybernetic Approach to Management, John Wiley \& Sons, Chichester.

Ethiray, S.K. and Levinthal, D. (2004), "Bounded rationality and the search for organizational architecture: an evolutionary perspective on the design of organizations and their evolvability", Administrative Science Quarterly, Vol. 49, pp. 404-37.

Fitzroy, P. and Hulbert, J. (2005), Strategic Management: Creating Value in Turbulent Times, Wiley, London.

Grant, R.M. (1996), "Toward a knowledge-based theory of the firm", Strategic Management Journal, Vol. 17, pp. 109-22.

Habermas, J. (1978), Knowledge and Human Interests, Heinemann, London.

Hamel, G. and Prahalad, C.K. (1989), "Strategic intent", Harvard Business Review, Vol. 67, pp. 63-76.

Hofstede, G. (1980), Culture's Consequences: International Differences in Work-related Values, Sage Publications, Beverly-Hills, CA.

Kickul, J. and Gundry, L.K. (2001), "Breaking through boundaries for organizational innovation: new managerial roles and practices in e-commerce firms", Journal of Management, Vol. 27, pp. 347-61.

Lane, P.J., Koka, B.R. and Pathak, S. (2006), "The reification of absorptive capacity: a critical review and rejuvenation of the construct", Academy of Management Review, Vol. 31, pp. 833-63.

Lanza, A. (2005), "Managing heterogeneity, allocative balance, and behavioural and technology concerns in competitive and cooperative inter-firm relationships", in Capasso, A., Dagnino, G.B. and Lanza, A. (Eds), Strategic Capabilities and Knowledge Transfer within and between Organizations, Edward Elgar, Cheltenham, pp. 17-34.

Luhmann, N. (1995), Social Systems, Stanford University Press, Stanford, CA.

March, J.G. and Simon, H. (1958), Organizations, John Wiley \& Sons, New York, NY.

Mills, D.Q. (1991), Rebirth of the Corporation, Wiley, New York, NY.

Newbert, S.C. (2007), "Empirical research on the resource-based view of the firm: an assessment and suggestions for future research", Strategic Management Journal, Vol. 28, pp. 121-46.

Nonaka, I. (1991), "The knowledge-creating company", Harvard Business Review, Vol. 69, pp. 96-104.

Nonaka, I. (1994), "A dynamic theory of organizational knowledge creation”, Organization Science, Vol. 5, pp. 14-37.

O'Reilly, C.A., Chatman, J. and Caldwell, D.F. (1991), "People and organizational culture: a profile comparison approach to assessing person-organization fit", Academy of Management Journal, Vol. 34, pp. $487-516$.

Obstfeld, D. (2005), "Social networks, the tertius lungens orientation and involvement in innovation", Administrative Science Quarterly, Vol. 50, pp. 100-30.

Parsons, T. (1971), The System of Modern Societies, Prentice-Hall, Englewood Cliffs, CA.

Peteraf, M.A. and Maritan, C.A. (2007), "Dynamic capabilities and organizational processes", in Helfat, C.E., Finkelstein, S., Mitchell, W., Peteraf, M.A., Singh, H., Teece, D.J. and Winter, S.G. (Eds), Dynamic Capabilities: Understanding Strategic Change in Organizations, Blackwell, Oxford, pp. 30-45.

Polanyi, M. (1967), The Tacit Dimension, Anchor Books, New York, NY.

Robbins, S.P. (2003), Organizational Behavior, Pearson Custom Publishing, Upper Saddle River, NJ. 
Sackmann, S.A. (1992), "Culture and subculture: an analysis of organizational knowledge", Administrative Science Quarterly, Vol. 37, pp. 140-61.

Schein, E.H. (1990), Organizational Culture and Leadership, Jossey-Bass, San Francisco, CA.

Schiuma, G. and Lerro, A. (2008), "Intellectual capital and company's performance improvement", Measuring Business Excellence, Vol. 12, pp. 3-9.

Schreyögg, G. and Kliesch-Eberl, M. (2007), "How dynamic can organizational capabilities be? Towards a dual-process model of capability dynamization", Strategic Management Journal, Vol. 28, pp. 913-33.

Teece, D.J. (2007), "Explicating dynamic capabilities: the nature and microfoundations of sustainable enterprise performance", Strategic Management Journal, Vol. 28, pp. 1319-50.

Teece, D.J., Pisano, G.G. and Shuen, A. (1997), "Dynamic capabilities and strategic management", Strategic Management Journal, Vol. 18, pp. 509-33.

Tushmann, M.L. (1977), "Special boundary roles in the innovation process", Administrative Science Quarterly, Vol. 22, pp. 587-605.

von Glasersfeld, E. (1987), The Construction of Knowledge: Contributions to Conceptual Semantics, Intersystems, Seaside, CA.

Wenger, E. (1998), Communities of Practice: Learning, Meaning, and Identity, Cambridge University Press, Cambridge.

Wernerfelt, B. (1984), "A resource-based view of the firm", Strategic Management Journal, Vol. 5, pp. 171-80.

Wiener, N. (1975), Cybernetics: or Control and Communication in the Animal and the Machine, The MIT Press, Cambridge, MA.

Williamson, O.E. (1975), Markets and Hierarchies: Analysis and Antitrust Implications, Free Press, New York, NY.

Winter, S.G. (2003), "Understanding dynamic capabilities", Strategic Management Journal, Vol. 24, pp. 991-5.

Zajac, E.J., Kraatz, M.S. and Bresser, R.K.F. (2000), "Modeling the dynamics of strategic fit: a normative approach to strategic change", Strategic Management Journal, Vol. 21, pp. 429-53.

\section{About the authors}

Marion Weissenberger-Eibl heads the Department of Innovation and Technology Management at University Kassel and is Director of the Fraunhofer Institute of Systems and Innovation Research (ISI) in Karlsruhe. Her research focus is innovation and technology management, strategic management and (knowledge) management. Marion Weissenberger-Eibl is the corresponding author and can be contacted at: marion@weissenberger-eibl.de

Johann Schwenk is a research associate and doctoral candidate at the Department of Innovation and Technology Management at University Kassel. His research focus is strategic management, innovation and knowledge management.

To purchase reprints of this article please e-mail: reprints@emeraldinsight.com Or visit our web site for further details: www.emeraldinsight.com/reprints 